\title{
EXPERIMENTS IN NONISOTHERMAL DIFFUSION OF MOISTURE IN WOOD ${ }^{1}$
}

\author{
John F. Siau \\ Professor of Wood Products Engineering \\ SUNY College of Environmental Science and Forestry, Syracuse, N.Y. 13210 \\ Fucheng Bao \\ Associate Professor \\ Institute of Wood Industry, The Chinese Academy of Forestry \\ Beijing, People's Republic of China \\ and \\ Stavros Avramidis \\ Graduate Student \\ SUNY College of Environmental Science and Forestry, Syracuse, N.Y. 13210
}

(Received August 1984)

\begin{abstract}
A series of nine experiments was performed with one surface of the wood specimen maintained at approximately $70 \mathrm{C}$ and the other at $29 \mathrm{C}$. The warm surface was exposed to relative humidities between $10 \%$ and $50 \%$. One series of four experiments was conducted with the cool surfaces exposed to relative humidities between $34 \%$ and $42 \%$, while those of the other series of five were exposed at $52 \%$ to $53 \%$. In both series, a reversal of flux direction was observed as the relative humidity of the warm surface was increased. The results were analyzed using the general sorption data presented in the USDA Wood Handbook using two equations, the first of which is based on a gradient of activated moisture content and the second on a gradient of chemical potential that contains an additional term to account for the effect of the temperature gradient. Both equations predicted the observed reversal of flux direction, but the chemical potential equation generally provided the better fit to the experimental results.
\end{abstract}

Keywords: Nonisothermal diffusion, activated moisture content, chemical potential, activation energy of diffusion.

\section{BACKGROUND AND THEORY}

A series of four nonisothermal experiments was carried out by Siau and Babiak (1983) and these were analyzed by using the general sorption data in the Wood Handbook (USDA 1955) by applying the equation based on a gradient of activated moisture content derived by Skaar and Siau (1981). A reasonable agreement was obtained between the theoretical and experimental fluxes. A later series of five experiments was performed by Siau and Jin (1985), and these were also analyzed using the Wood Handbook data by applying both the activated-moisture-content equation and a modified one based on a gradient of chemical potential. The theoretical calculations were in fair agreement with the experimental results.

This research was supported by the National Science Foundation.

Wood and Fiber Science, 18(1), 1986, pp. 84-89

(C) 1986 by the Society of Wood Science and Technology 
TABLE 1. Summary of data on nonisothermal diffusion experiments.

\begin{tabular}{|c|c|c|c|c|c|c|c|c|c|}
\hline Exp. no. & B1 & B2 & B3 & B4 & $\mathrm{Cl}$ & $\mathrm{C} 2$ & $\mathrm{C} 3$ & $\mathrm{C} 4$ & C5 \\
\hline${ }^{*} \mathrm{~T}_{\mathrm{w}},{ }^{\circ} \mathrm{C}$ & 68.3 & 69.2 & 70.1 & 69.9 & 67.0 & 69.6 & 69.8 & 69.9 & 70.2 \\
\hline${ }^{*} \mathrm{~T}_{c},{ }^{\circ} \mathrm{C}$ & 28.5 & 29.3 & 28.3 & 29.2 & 27.6 & 27.8 & 27.9 & 28.0 & 28.7 \\
\hline $\begin{array}{l}\mathrm{T} \text {, diffusion cup, } \\
{ }^{\circ} \mathrm{C}\end{array}$ & 13.3 & 13.3 & 13.3 & 13.3 & 18.0 & 18.0 & 18.0 & 18.0 & 18.0 \\
\hline $\mathrm{H}_{\mathrm{w}}, \%$ & 11.3 & 20.0 & 32.4 & 47.4 & 10.5 & 21.3 & 34.0 & 42.4 & 49.8 \\
\hline $\mathrm{H}_{c}, \%$ & 36.1 & 33.7 & 39.4 & 42.1 & 51.7 & 51.9 & 53.1 & 53.3 & 54.6 \\
\hline $\mathrm{M}_{\mathrm{w}}, \%$ & 2.0 & 3.3 & 4.7 & 6.4 & 2.1 & 3.4 & 4.8 & 5.8 & 6.7 \\
\hline $\mathrm{M}_{\mathrm{c}}, \%$ & 6.8 & 6.5 & 7.3 & 7.7 & 9.3 & 9.3 & 9.5 & 9.5 & 9.7 \\
\hline $\begin{array}{l}\text { Exp. flux, } \\
\mathrm{g} / \mathrm{cm}^{2} \mathrm{~s} \times 10^{9}\end{array}$ & 3.7 & 1.4 & -6.5 & -13.6 & 12.6 & 8.0 & 4.8 & 3.6 & -8.2 \\
\hline
\end{tabular}

The equation based on a gradient of activated moisture content $\left(\mathrm{dM}^{*} / \mathrm{dx}\right)$ proposed by Skaar and Siau (1981) may be written as:

$$
J=-K_{M}\left[\frac{M E_{b}}{T(R T+70 M)} \frac{d T}{d x}+\frac{d M}{d x}\right]
$$

Gradient of activated moisture content

where $E_{b}=$ activation energy for bound-water diffusion, cal/mol; $J=f l u x, g /$ $\mathrm{cm}^{2} \mathrm{~s}, \mathrm{~K}_{\mathrm{M}}=$ coefficient for bound-water diffusion based on a gradient of percent moisture content, $\mathrm{g} /(\mathrm{cm} \mathrm{s} \%) ; \mathrm{M}=$ percent moisture content; $\mathrm{R}=$ universal gas constant; $\mathrm{T}=$ Kelvin temperature; $\mathrm{x}=$ distance from cool surface, $\mathrm{cm}$.

The chemical-potential equation is a modified form of Eq. (1) of Siau (1980) in which the thermal heat of transfer $\left(Q^{*}\right)$ is assumed to be equal to the activation energy for bound-water diffusion $\left(E_{b}\right)$. The value of this latter quantity is taken as $(9,200-70 \mathrm{M}) \mathrm{cal} / \mathrm{mol}$ in agreement with the determinations of Stamm (1959) and Choong (1963). This latter equation (Siau 1984) may be written in similar form to Eq. (1) as:

$$
J=-K_{M}\left[\frac{H}{R T}\left(\frac{\partial M}{\partial H}\right)_{T}\left(\frac{d \mu_{1}^{\circ}}{d T}+\frac{E_{0}+E_{L}+E_{b}}{T}+R \ln H_{0} / 7600\right) \frac{d T}{d x}+\frac{d M}{d x}\right]
$$

Gradient of chemical potential

where $E_{L}=$ molar heat of sorption of bound water, $E_{0}=$ molar heat of vaporization of free water, $\mathrm{H}=$ percent relative humidity, $\mathrm{p}_{0}=$ saturated vapor pressure at $\mathrm{T}$, $\mathrm{cm} \mathrm{Hg}$.

\section{PROCEDURE}

The experimental setup was similar to that described by Siau and Babiak (1983) except for significantly improved instrumentation and control of the relative humidities in contact with the wood surfaces. Temperatures were measured using a thermister readout with a resolution of $0.1 \mathrm{C}$. A fan was used to assure adequate air circulation in the measurement of the wet-bulb temperature within the controlled chamber, which was a $4 \frac{1}{2} 2$-cubic-foot Climate Lab produced by Parameter 


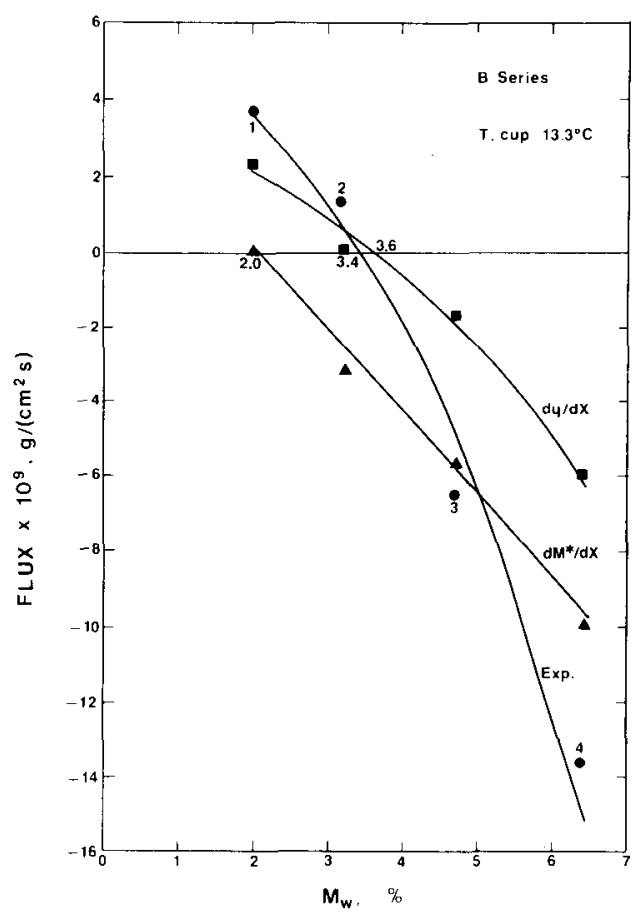

FIG. 1. A plot of experimental and theoretical fluxes vs. equilibrium moisture content on the warm side of the specimen $\left(\mathrm{M}_{\mathrm{w}}\right)$. Theoretical results were calculated from Eqs. (1) and (2). The diffusioncup temperature was maintained at $13.3 \mathrm{C}$. The experimental fluxes are indicated by dots that are numbered corresponding to the four experiments in the B series.

Generation and Control, Inc. The warm surface of the specimen was in equilibrium with the conditions in the chamber. The latter was placed in a room maintained at $20 \pm 1 \mathrm{C}$ with the relative humidity held between $30 \%$ and $50 \%$ with a dehumidifier. The relative humidity adjacent to the cool side of the test specimen was measured with lithium-chloride-coated sensors manufactured by Newport Scientific. These were previously calibrated over solutions or in the controlled chambers. The relative humidity in equilibrium with the cool surface was controlled by cooling the diffusion-cup water reservoir by means of a thermoelectric cooling chip to maintain the desired saturated vapor pressure over the water surface.

In the first series (B) this temperature was maintained at $13.3 \mathrm{C}$, while in the second series (C) it was controlled at 18.0 C. Two matched specimens of Pinus monticola Dougl. (western white pine) were used, with one specimen in each series. The specific gravity was 0.38 after vacuum drying to equilibrium at $50 \mathrm{C}$. The duration of the experiments was approximately two weeks.

RESULTS

The average conditions maintained during the experiments are revealed in Table 1. The diffusion-cup temperature for the B-series resulted in relative humidities 


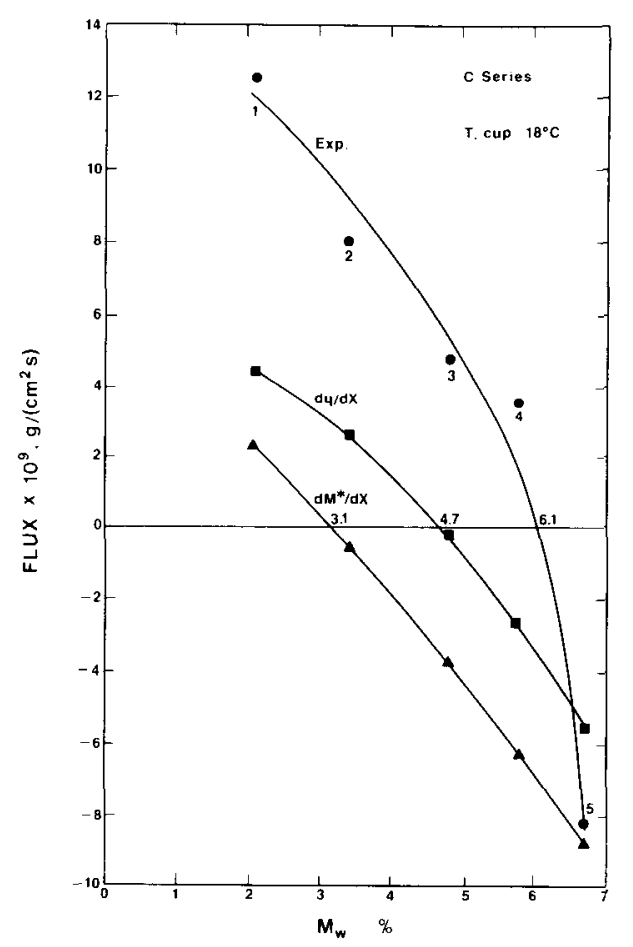

Fig. 2. Experimental and theoretical fluxes as a function of $M_{w}$ for the five experiments of the $C$ series in which the temperature of the diffusion cup was maintained at $18.0 \mathrm{C}$.

on the cool surfaces between $34 \%$ and $42 \%$, with the variations due to differences in flux and cool-surface temperatures. The relative humidities on the warm surface were maintained between $11 \%$ and $47 \%$ for the four experiments in this series. In the five experiments of the C-series, the higher diffusion-cup temperature resulted in relative humidities between $52 \%$ and $55 \%$ on the cool surfaces. Relative humidities on the warm surfaces were varied between $11 \%$ and $50 \%$.

In Table 2 the experimental fluxes are compared with the theoretical values calculated from Eqs. (1) and (2) by the Euler method as explained by Siau and

TABLE 2. Summary of experimental and theoretical fluxes.

\begin{tabular}{|c|c|c|c|c|c|}
\hline \multirow[b]{2}{*}{ Exp. no. } & \multirow[b]{2}{*}{$\mathrm{M}_{\mathrm{w}}$} & \multirow[b]{2}{*}{$\mathbf{M}_{\mathrm{c}}$} & \multicolumn{3}{|c|}{ Flux, $\mathrm{g} / \mathrm{cm}^{2} \mathrm{~s} \times 10^{9}$} \\
\hline & & & Exp. & $\mathrm{dM}^{*} / \mathrm{dx}$ & $\mathrm{d} \mu / \mathrm{dx}$ \\
\hline B1 & 2.0 & 6.8 & 3.7 & 0.0 & 2.4 \\
\hline B2 & 3.3 & 6.5 & 1.4 & -3.1 & 0.1 \\
\hline B3 & 4.7 & 7.3 & -6.5 & -5.7 & -1.7 \\
\hline B4 & 6.4 & 7.7 & -13.6 & -10.0 & -6.0 \\
\hline $\mathrm{Cl}$ & 2.1 & 9.3 & 12.6 & 2.4 & 4.6 \\
\hline $\mathrm{C} 2$ & 3.4 & 9.3 & 8.0 & -0.5 & 2.7 \\
\hline $\mathrm{C} 3$ & 4.8 & 9.5 & 4.8 & -3.7 & -0.1 \\
\hline $\mathrm{C} 4$ & 5.8 & 9.5 & 3.6 & -6.3 & -2.6 \\
\hline $\mathrm{C5}$ & 6.7 & 9.7 & -8.2 & -8.7 & -5.5 \\
\hline
\end{tabular}




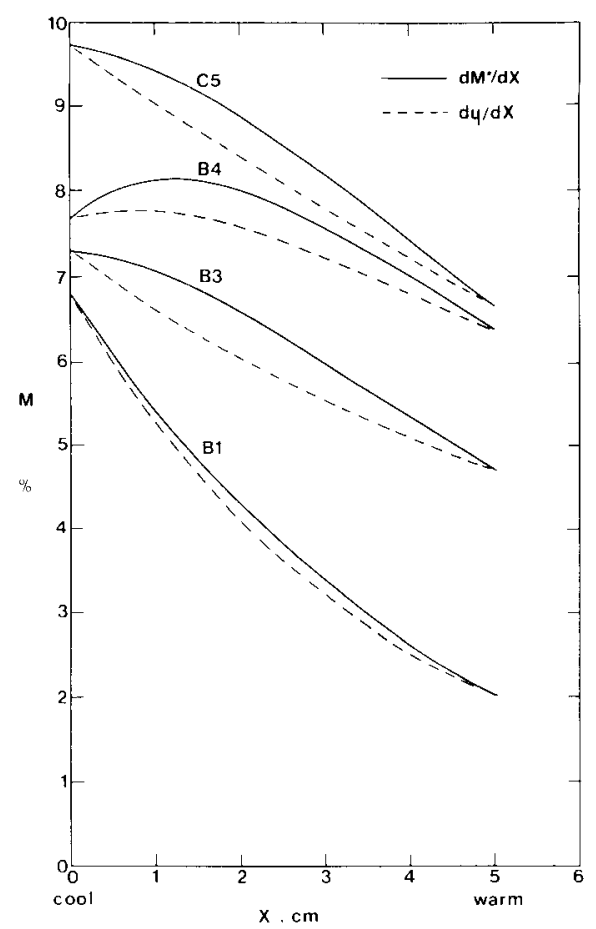

Fig. 3. Moisture profiles in Experiments B1, B3, B4, and C5 as calculated from Eqs. (1) and (2).

Babiak (1983). These results are presented graphically in Figs. 1 and 2, in which the flux is plotted as a function of the moisture content on the warm surface $\left(M_{w}\right)$ for each series. The plots were made in this manner because the moisture contents on the cool side $\left(\mathrm{M}_{\mathrm{c}}\right)$ were maintained approximately constant in each series.

Figure 1 indicates that the experimental flux changed direction at a value of $M_{w}$ of $3.4 \%$. Calculations based on a gradient of activated moisture content result in expected flux reversal of $\mathrm{M}_{\mathrm{w}}=2.0 \%$, while those based on chemical potential predicted reversal at $\mathbf{M}_{\mathrm{w}}=3.6 \%$. The flux values calculated from Eq. (2) were in better agreement with the experiments at lower values of $M_{w}$ while Eq. (1) gave better agreement at higher values of $\mathbf{M}_{\mathrm{w}}$.

Figure 2 reveals that, in the $\mathrm{C}$ series, experimental flux reversal occurred at $M_{w}=6.1 \%$, while Eq. (1) based on activated moisture content predicted reversal at $\mathrm{M}_{\mathrm{w}}=3.1 \%$ and Eq. (2) gave a value of $4.7 \%$. The values of flux calculated from Eq. (2) were also closer to experiment than those from Eq. (1) except for Experiment C-5.

It is concluded that Eq. (2) based on chemical potential gave a better agreement with the experimental results than Eq. (1) in both the B and C series. It must be realized, however, that this conclusion is based on the use of the general Wood Handbook sorption data, which may not be typical of the western white pine specimens used in these experiments. It would be much more meaningful to base the comparison on our own experimental sorption data from specimens closely matched to those used in the experiments. Such sorption data are now being accumulated and their use should lend much more validity to future results. 
Plots of the moisture profiles calculated from Eqs. (1) and (2) are revealed in Fig. 3. In all cases the activated-moisture equation gave higher values of $\mathbf{M}$ for a given value of $x$ than did the chemical-potential equation in agreement with the results of Siau and Jin (1985). It is interesting to note that both equations predicted a maximum value of $M$ within the specimen in Experiment B4. There was also a large increase in experimental flux between B3 and B4 corresponding to a relatively small increase in $\mathrm{H}_{\mathrm{w}}$ from $32.4 \%$ to $47.4 \%$. When $\mathrm{H}_{\mathrm{w}}$ was increased to $63 \%$ in Exp. B5, a much greater flux of $-46 \times 10^{-9} \mathrm{~g} / \mathrm{cm}^{2} \mathrm{~s}$ occurred, which caused a loss of control of the relative humidity on the cool side of the specimen and condensation in the plastic tube adjacent to the diffusion cup, which made accurate monitoring of the experiment impossible. An excessive time (over one month) was required to attain a constant flux. In addition to this, a much higher theoretical peak moisture content within the specimen was calculated than in B4, leading to the conclusion that condensation had probably occurred within the specimen. It was therefore concluded that there is a practical upper limit to the relative humidity in equilibrium with the warm surface of the specimen in a nonisothermal diffusion experiment. In the B-series, this upper limit was probably between $45 \%$ and $60 \%$. For these reasons, the results of Experiment B5 were omitted from this analysis.

Further similar experimentation is planned with a greater range of partial vapor pressures on the cool side, along with sorption studies of specimens matched to those used in the nonisothermal experiments.

\section{REFERENCES}

CHOONG, E. T. 1963. Movement of moisture through a softwood in the hygroscopic range. For. Prod. J. 13(11):489-498.

SIAU, J. F. 1980. Nonisothermal moisture movement in wood. Wood Sci. 13(1):11-13.

1984. Chemical potential and nonisothermal diffusion. Letter to the editor. Wood Fiber Sci. 16(4):628.

- AND M. BABIAK. 1983. Experiments on nonisothermal moisture movement in wood. Wood Fiber Sci. 15(1):40-46.

—, AND Z. JIN. 1985. Nonisothermal moisture diffusion experiments analyzed by four alternative equations. Wood Sci. Technol. (in press).

SkaAR, C., ANd J. F. Siau. 1981. Thermal diffusion of bound water in wood. Wood Sci. Technol. 15:105-112.

Stamm, A. J. 1959. Bound-water diffusion into wood in the fiber direction. For. Prod. J. 9(1):27-32.

U.S. DePt. OF Agriculture. 1955. Wood Handbook. U.S.D.A. Handbook No. 72, U.S. Government Printing Office. 